\title{
Potential Explanations for the Black-White Achievement Gap in U.S. Public Education
}

\begin{abstract}
:
The present article probes into the magnitude of the black-white academic achievement gap and investigates the different probable explanations that laid the foundations for the academic discrepancies between black students and their more affluent counterparts in U.S. public education. In fact, the potential explanations that planted the seeds of the black-white achievement gap are dissimilar and varied. There is a wide range of factors and a huge array of miscellaneous explanations, or rather theories that can be held accountable for the present African American underachievement in U.S. public schools. The achievement gap issue necessitates a profound and strong comprehension of the gap's grounds. There are no unanimously conventional causes of the black-white achievement gap. There is no consensus of what really caused the Black-white achievement gap in U.S. public education. In fact, explanations vary broadly along ideological, racial, and even political lines. Of the numerous explanations that have been provided, some are the outcome of scrupulous analysis and constructive study. Others stem from ideological- or some might consider them biased- positions. Indisputably, these beliefs and views are profoundly held. The explanations usually provided to account for the current gap spring from socio-cultural, socioeconomic, pedagogical, and genetic roots. Racism, genetic factors, black oppositional culture, socioeconomic and sociocultural attributes, and educational factors are mere possible explanations. We argue in this article that school-based factors are deemed as the most potential explanations for the black-white achievement gap in U.S. public education. We believe that operational educational practices can surmount all other problems and that all children can learn when provided with the proper pedagogical sustenance.
\end{abstract}

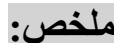

يعنى هذا المقال بالبحث في حجم فجوة التحصيل الأكاديمي بين الطلاب البيض و السود ويحقق في

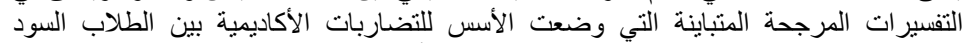

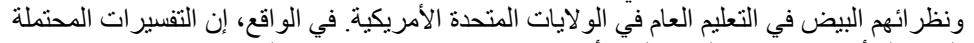

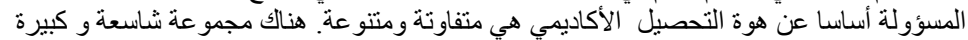

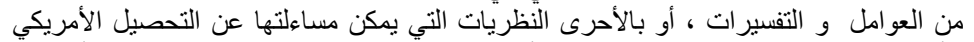

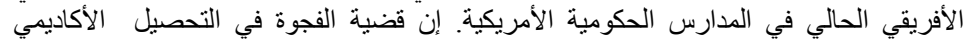

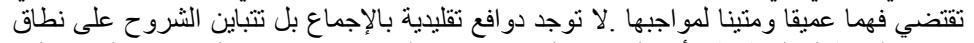

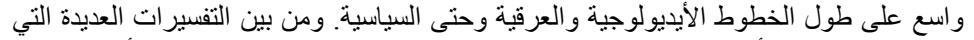

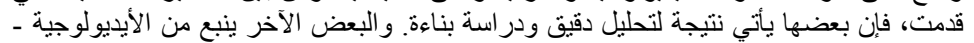

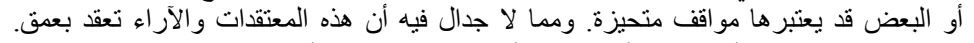

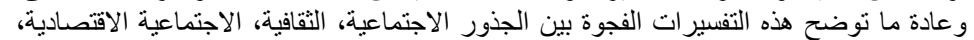

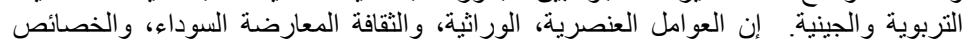

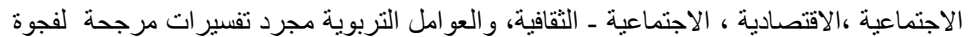

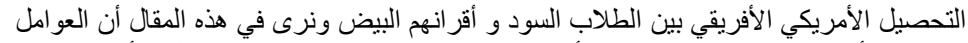

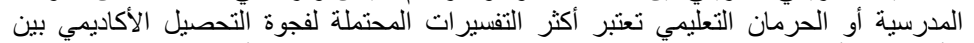

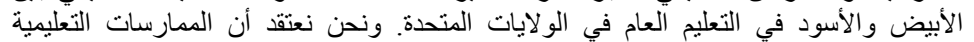

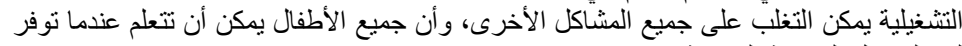
لهم الوسائل التربوية المناسبة النغلية

\author{
Fatima Hamadouche \\ Département de la langue Anglaise \\ Université des Frères Mentouri \\ Constantine 1
}

\section{Introduction :}

The achievement gap commonly points to the dissimilarities among demographic groups on state and nationwide academic tests. The achievement gap comprises differences between deprived versus advantageous students, low-income versus more affluent students, students with disabilities versus those without disabilities. In this article, however, the achievement gap refers specifically to the disparities between the achievement of white students and black students on academic

assessments such as Scholastic Aptitude Test (SAT) scores- a test taken in the U.S. to measure students' aptitudes before entry into college- and American College Testing (ACT) scores- a standardized test for high school performance and

college admissions in the United States, and graduation rates. In spite of the existence of the achievement gap issue amongst

other racial and ethnic minorities in the United States, namely Asian and Hispanic students, the emphasis in here is to scrutinize the difference in academic performance specifically

among black students, when compared with their white peers, as their underachievement is so distinct and lags behind the achievement of white students. 
In reality, African American underachievement in U.S. public education is an issue that has been widely explored by a considerable number of researchers. Investigating different causes and grounds that planted the seeds of the academic achievement gap between black students and their white cohorts in American public schools has preoccupied a wide range of scientists, scholars, economists, sociologists, anthropologists, education experts and politicians. They all offered dissimilar probable arguments that might account for the black-white achievement gap. Some provided potential justifications are substantial as they arise from well- documented research and constructive studies; others are plain speculations and biased ideologies. What has to be retained, however, is that there is no sole common explanation of the blackwhite achievement gap; what follow are mere plausible theories and arguments that might explain the extensive academic achievement discrepancies between black and white students.

\section{Attributes of African American Underachievement}

Achievement gaps are of particular concern since academic performance in the K-12 grades is a precursor to college access and accomplishment in the labor market; accordingly, a college degree has become increasingly imperative in the labor market, and has become ever more vital for economic mobility. Simultaneously, access to college, mainly to more selective colleges, has become progressively more contingent on students' test scores and academic achievement. Owing to the growing significance of academic achievement, the white-black test score gap now elucidates virtually all of the white-black variance in college enrollment and most or all of the white-black dissimilarities in earnings. Eradicating racial achievement gaps is therefore indispensable for abridging broader racial discrepancies in U.S. society.

A deep examination of the black-white achievement gap is of a great significance; indisputably the main question would not be whether the gap exists, but rather whether it persists. It is almost taken for granted that there is an achievement gap between black and white students. This fact does not stem from nowhere; the legacies of slavery and racism still have their vestiges in the American society and in the American people's mind. The problem, however, is that a considerable number of people are unaware of the magnitude of this thorny issue as they are elusively conscious that black and white students, on average, achieve differently in schools. Moreover, despite the heated debate of the black-white achievement in the K-12 educational community and in a few corners of academia, startlingly few people have granted much thought to this issue. Even those who are well-informed about the gap's reality and its magnitude frequently consider that the divide cannot be narrowed until poverty is eliminated and all vestiges of racism in America are eradicated. Investigators Paige and Witty clearly asserted that: 
There is a quagmire of conflicting views to explain the blackwhite achievement gap. Which view one favors can depend on many different variables, not the least of which are racial allegiances and political ideology. But the whole issue boils down to whether or not one believes all children can learn...but the degree to which one believes that all children can learn seems to be the determinant of which explanation for the gaps' existence one finds most compelling. (73)

Scientists and theoreticians alike have scrutinized most features of human character, performance, and endeavor to attempt to identify significant links and treatments for the enormous dissimilarity between African American and white student attainment. Included among the most distinguished recurrent justifications are racism and genetic factors, black identity and oppositional culture, socioeconomic status and disparities, sociocultural attributes, and educational factors. In the section that follows, the literature on each of these subject variables is scrutinized for their likelihood as explanations for the achievement of African Americans and the gaps between their performance and that of their white peers. Though the hierarchy of the different explanations inhere is interchangeable, the placement of the most subjective or rather less convincing arguments at the outset is meant to shed more light on the most potent explanations by the end. Racist attitudes and their inevitable aftermath on African Americans' rocky experience in the U.S. are to be approached as first probable explanations that planted the seeds of academic disparities between black and white students in American public education.

\section{A. Racism}

A considerable number of researchers maintain that African American experience in the U.S. is replete with obstacles which hindered them from attaining high at schools. In a society that is as racially stratified as America, whites' discriminatory attitudes against blacks and the long history of bondage, Jim Crowism, and racism have inevitable consequences on African American students' academic achievement. After meticulously probing into the research literature, John Diamond, in his paper "Are we Barking up the Wrong Tree?" contends that in an attempt to understand achievement gaps one should rather understand the academic achievement restraints confronted by African Americans due to the racial stratification of society. He confirms that "Black students face a racialized educational terrain that creates material and symbolic disadvantage for them" and further announces that "These disadvantages are embedded in our social fabric and reflected in our social structures, schools, and perceptions of race and intellectual ability (10)."

Diamond clarifies some of the distinguishing experiences of African American students founded on their race: first, the schools that black students go to are frequently less conductive to their scholastic success (Diamond and 
Spillane 1145-1176). Second, while the mechanisms are complex to elucidate, school segregation- specifically the concentration of low-income African American students in a number of schools- contributes to lower results for students attending these schools even after controlling for students' previous attainment (Bankston and Caldas 535-555), and schools in the United States have become more and more re-segregated in recent years (Orfield and Eaten 424). And lastly, African Americans pay higher costs for less decent housing that is more likely to be situated in isolated neighborhoods; they have inferior levels of employment and professional flexibility, lower home loan supports, and more undesirable connections with the legal system (Bonilla-Silva).

A wide array of investigators contend that the African American experience is dissimilar to any other experience of a minority group in the United States and that this dissimilarity plays a vital role in African American trails to success. As opposed to Latin or Asian immigrants, who are frequently considered as voluntary immigrants- individuals who were determined to go to the United States, either for better job openings or to follow an educationAfrican Americans are regarded as involuntary immigrants, compelled to enter the United States by someone else's hand (Ogbu "Racial Stratification" 26498). Therefore, their views of the American dream and American success might vary from those experienced by other minority groups in the USA. Black Americans are hence considered to have shaped a combined identity that is defined by domination, leading to many blacks perceiving and fearing the acceptance of "white ways" as a device for breaking African American unity and identity.

Other scholars claim that the marginalization and communal illtreatment of African Americans by whites merely on the foundation of skin color has impacted some black individuals by molding the opinions they hold of themselves and those around them. As the endeavors made by African Americans to gain deserved places in academia and the workforce are rebuffed, a larger number assumes these beliefs (Ogbu "Racial Stratification" 264-98). They might experience feelings of uncertainty and submission as they begin to question their intelligence in comparison with whites (Ogbu "Racial Stratification" 264-98). With the many impediments blacks experience as a result of a racially stratified society, joined with the hurdles they might generate for themselves through internalization of chauvinistic beliefs, the black-white achievement gap is predictable. Moreover, racism is not the only probable hurdle that stood on the way of African Americans' success in U.S. public schools, genetic explanations, though scientifically rejected, are very commonly offered to account for the persistent black-white achievement gap.

\section{B. Genetic Factors}

Furthermore, a number of scientifically alleged researchers attribute the existing and persistent wide achievement gap between blacks and whites to 
genetic factors proclaiming that intelligence is biologically determined by race and therefore blacks are intellectually inferior to whites. In reality, such kind of biased arguments pore over what we may call "scientific racism." Actually, the controversial issue of racial differences in intelligence was brought to discussion again by the threshold of the $21^{\text {st }}$ century when American psychologist Richard Herrnstein and American political scientist Charles Murray published their book the Bell Curve: Intelligence and Class Structure in American Life in 1994. The authors were reported throughout the popular press as arguing that IQ differences are genetic and that both genes and the environment have something to do with racial differences.

"Genetics" as a justification of the black-white achievement gap is derived from the writings of the plainspoken social critic Mano Singham, whose influential article, "The Canary in the Mine," is frequently cited by psychologists and education scholars when raising the issue of the achievement gap (Singham 9-15). The philosophy here is that the gaps in black and white academic achievement, together with other educational achievement discrepancies between black and white students, do not stem from educational opportunity, economics, culture, or environmental dynamics, but from a simple act of nature: blacks are intellectually inferior to whites. They contend that genetics basically did not endow blacks with sufficient cerebral horsepower to compete scholastically with whites. Therefore, there are no resolutions to the existing achievement gap with this explanation (Paige and Witty 64-65).

The debate over race and intelligence can be drawn all the way back to French psychologist Alfred Binet, who is accredited with devising the first intelligence test in the early twentieth century (Binet). Dispute over the topic has followed since then, and Richard J. Herrnstein threw fuel on the fire when their book The Bell Curve was published in 1994. Herrnstein and Murray's fundamental argument is that human intelligence is significantly influenced by both hereditary and environmental dynamics and is a better predictor of numerous personal factors, comprising involvement in crime, financial income, job performance, and birth out of wedlock, than are an individual's parental socioeconomic status, or scholastic level. They claim as well that those with high intelligence, the "cognitive elite", are becoming isolated from those of average and below-average intelligence. The book was provocative, particularly where the authors wrote about racial disparities in intelligence and debated the repercussions of those differences. The authors were reported all through the popular press as proclaiming that these IQ differences are genetic. They wrote in chapter 13: "It seems highly likely to us that both genes and the environment have something to do with racial differences." The book's title originates from the bell-shaped normal distribution of intelligence quotient (IQ) scores in a population. A huge number of people rallied both in condemnation 
and defense of the book and a large array of critical texts were written in response to the work a short period after its publication.

Reacting to the debate initiated by The Bell Curve, the American Anthropological Association (AAA) made its response on the issue clear by espousing a "Statement on 'Race' and Intelligence" in December 1994. It confirmed its profound concern concerning the public debates that pretend that intelligence is determined by race, and highlighted that "Such discussions distract public and scholarly attention from and diminish support for the collective challenge to ensure equal opportunities for all people, regardless of ethnicity of phenotypic variation." Furthermore, the American Psychological Association's reaction was comparable. It indicated that, "Regarding genetic causes, they noted that there is not much direct evidence on this point, but what little there is fails to support the genetic hypothesis" (American Psychological Association, The View of the American Psychological Association).

Though the majority of anthropologists and psychologists provide a tiny backing for genetic explanations of the achievement gap, the notion still lingers profoundly entrenched in the minds of a wide array of the American population. In spite of the absence of scientific support, numerous people find it difficult to discard these ideas in the face of persistent discrepancies in performance between black and white students (Paige and Witty 66). Racist attitudes and genetic factors are not the only probable explanations that lie behind the black-white achievement gap. Forces within the black community and the oppositional culture theory are evenly ascribed to clarify the current academic inconsistencies between black and white students.

\section{Black Identity and Oppositional Culture}

A large array of investigators and theoreticians ascribe the low academic performance of African American students to a wide range of dynamics that do exist and persist within the black community. Among the most common theories are: "relational adaptation", "effort and reward" "acting white", "oppositional culture", "anti-intellectualism", and others. The arguments provided rationalize the poor performance of blacks at schools on the basis of forces within their own community. Such notions as working hard does not pay or that performing well in school is "acting white", the push for scholastic underperformance as a reaction to peer pressure, and also the fear of stereotype-threat phenomenon are all the outcome of the long history of bondage and racism in the U.S. and are initially derived from whites having deprived blacks of education for centuries, namely through enforced illiteracy and enslavement of the mind.

John Ogbu, a prominent professor of anthropology at the University of California, Berkeley, was interested in a wide range of dynamics that he 
supposed elucidated low performance among African American students (Ogbu "Racial Stratification" 264-298). Chief among these were forces within the African American community itself. Within this set of justifications, Ogbu lists three potential explanations: black folk theories of effort and reward, black relational adaptations, black belief that school learning is "acting white." The first of Ogbu's three possibilities- black folk theories of effort and rewardimplies that blacks have developed a folk theory which assumes that hard work does not pay. It is contradictory to "effort optimism," which is the conviction that rewards are related to the extent of action put into a task. His second possibility, Ogbu makes use of the phrase "relational adaptations" to portray the techniques African Americans have adjusted to white society. His third of three possibilities "acting white"_contains Ogbu's interpretation that African Americans have developed an "oppositional culture" that is compared to school standard English and school success with white culture and language. The notion that performing well in school is "acting white" leads African American students deliberately performing less well than they could do in order not to be regarded by their African American peers as being isolated from their black identity ("Racial Stratification" 264-98).

Large arrays of theories have arisen to elucidate the black-white achievement gap. Among the most popular, though not the most convincing, has been the oppositional culture theory. This theory, when attributed to African American students, has frequently emphasized peer pressure and particularly the charge by peers that serious students are in effect "acting white." This phenomenon was originally reported by prominent anthropologist Signithia Fordham and John Ogbu (1986) as a possible explanation for the achievement gap. Their research led them to determine that when highachieving African American students are confronted with the burden of peer pressure arising from being described as "acting white," they reply by developing oppositional orientations and tactics to schooling that are counterproductive. Though this interpretation has been a darling of broadcast media, the confirmation of the view is at best unconvincing. As a matter of fact, considerable current evidence has been created and proposes that such behaviors are not persistent among African American students, nor are they more predominant among African Americans than among students of other racial/ethnic backgrounds (Carter). Some have contended that it is not essentially a burden of acting white, but somewhat, a burden of high achievement that students of all races and ethnic groups are faced with (Tyson, Darity and Castellino 582-605).

In 1986, Signithia Fordham and John Ogbu declared in their article Urban Review: "Apparently, Black children's general perception that academic pursuit is 'acting white' is learned in the Black community. The ideology of the community in regard to the cultural meaning of schooling is, therefore, 
implicated and needs to be reexamined" (176-206). By means of dissimilar terminology, other academics and social philosophers have pronounced analogous opinions. John McWhorter, author of Losing the Race: Self Sabotage in Black America, is one of them. He confidently affirms that "a culturally embedded wariness of scholarly endeavor is the primary cause of the alarmingly persistent achievement gap between black students and most others" (135). He calls this phenomenon "anti-intellectualism" and proclaims that this is not just an inner-city phenomenon but one that "permeates the whole of black culture, all the way up the social class" (83). McWhorter states that this anti-intellectualism "is inherited from whites having denied education to blacks for centuries, and has been concentrated by the Separatist trend, which in rejecting the 'white,' cannot but help to cast school and books as suspicious and alien, not to be embraced by the authentically 'black' person" (83).

The former American President, then Senator Barack Obama gave the idea currency in his crucial speech before the 2004 Democratic National Convention, when he declared, "Go into any inner-city neighborhood, and folks will tell you that government alone can't teach kids to learn. They know that parents have to teach, that children can't achieve unless we raise their expectations and turn off the television sets and eradicate the slander that says a black youth with a book is acting white" ("The Audacity of Hope"). Obama's remarks triggered a tidal flood of pro-and-con debates and academic work about "acting white." Education and other academic heavyweights staked out their attitudes as to whether or not there really is an acting-white phenomenon that hinders African American students' scholastic achievement in school (Paige and Witty 67).

For numerous students, school is an environment with incompatible expectations and standards. One expectation is for high attainment, as highlighted by teachers, administrators, parents, and frequently by students themselves. Oppositely, among peers, academic disengagement, rather than attainment, is stimulated and understood to be "cool" (Ogbu "Black American Students in Suburb"). Therefore, researchers Tyson, Darity, and Cstellino focus on a difference they feel must be made between combining a common attitude pushing mediocrity versus an attitude toward educational achievement that is understood to be distinctive within a particular racial group; namely among black students. Accordingly, they divide the view of oppositional culture into three categories of oppositionality: general, racialized, and class-based. General oppositionality is the push for educational underperformance, in reaction to taunts such as "dork" and "nerd," a phenomenon that is found across all youth groups, irrespective of race, ethnicity, or social class.

Racialized oppostionality would be what Fordham and Ogbu have described as the "burden of acting white," where black students reply with 
academic underperformance due to taunts such as "Oreo"-meaning that these students are vigorously attempting to mimic, or become, their white cohorts. Finally, class-based oppositionality emphasizes more social class, making it a common culture across all racial groups; students are taunted with labels such as "snooty" and other words demonstrating that they feel that they are better than their counterparts. The taunts- whether they are socially, racially, or class motivated-are persistent reminders of the responses and performances that are considered tolerable by one's peers. Subsequently, many children react to the remarks and strive for educational disengagement and underachievement.

There have also been conducted researches that reveal that "acting white" is not a persuasive cause in African American underachievement. But these studies use self-reported student statistics from the National Educational Longitudinal Study (NELS), which is integrally less consistent. There is a struggle between academic achievement and the black identity in the African American community that establishes one of the main explanations for the black-white achievement gap. Though this is not the only cause of the gap, it is one of the most significant causes (Paige and Witty 68-69). Researcher Jason Osborne of the University of Oklahoma provides a connected explanation for the underachievement of black students comparative to their white peers. Osborne contends that the underachievement of underprivileged and stereotyped groups is a result of the stereotype-threat phenomenon. Stereotype threat is a fear that one's behavior will approve a stereotype which has been attributed to the group to which one belongs. Most students experience a certain amount of apprehension when confronted with taking a test that has relevance to their well-being.

In Osborne's study, the data revealed that students who belong to groups with negative academic stereotypes become anxious not only about the potential for individual humiliation and failure but also the potential for approving the negative group stereotype (Osborne 291-310). Not astonishingly, this supplementary anxiety further erodes their achievement potential, fueling the vicious phase of underachievement. In the situation of African Americans, who are clearly conscious that they are members of a stereotyped group believed to be mentally inferior to whites, the test symbolizes not only a personal jeopardy but also a danger for the whole group (Paige and Witty 71). There is rising empirical evidence that enhances Osborne's affirmation that underprivileged minorities do, in fact, experience higher levels of test anxiety when confronted with a test identified to be, or even supposed to be, an assessment of their intellectual or academic competence (293). In spite of the abundant deeply-conducted research and thoughtful studies on black identity and oppositional culture issues as potent attributes to the current black-white achievement gap, the arguments offered remain merely inconclusive with the emergence of further theories that rather place more importance on socio- 
economic status and economic disparities between the black white ethnic communities.

\section{Socioeconomic Status and Disparities}

Among the soundest explanations of the startling black white academic disparities in schools are socioeconomic status and the subsequent disparities between blacks and whites. Advocates of such attributes argue that educational achievement is potently associated with economic status as it dictates the environments, resources, and opportunities that children come across as they grow up. They proclaim that lower socioeconomic status and lower academic performance are intimately linked and that poverty has been constantly related to the achievement gap. For them, poverty has detrimental effects on schooling and leads inevitably to poor academic performance. They affirm that a family's socioeconomic status is often impacted by parent academic achievement and that poor families are less likely to invest in educational enrichment items. They also assert that social class affects the ability to provide the essential support for children to succeed academically and offer several theories about the interplay of social class and academic achievement. They evenly proclaim that stability in household and neighborhood income may have an impact on males in school.

Various commonly held justifications of the black-white achievement gap have as their basis socioeconomic status and inequalities between the two ethnic groups. Fundamentally, the argument is that the gap is produced by the long history of economic discrepancies between the two communities, tracing back to slavery. Those who approve of this explanation refer to the history of coercion that blacks have had to undergo. They point to such dynamics as blacks being lawfully forbidden from learning to read during bondage, being compelled to attend poor schools, being constrained to the constitutionally reinforced separate-but-equal regulations, being obliged to work in the fields when white children were in school, and other similar circumstances. They support their argument by highlighting the research that plainly backs the fact that educational attainment correlates more intensely with economic status than with any other particular variable (Paige and Witty 60).

Socioeconomic status is a crucial issue for the achievement gap discussion since it dictates the environments, resources, and openings that children meet as they grow up. Black children are more likely to live in deprived households than white children. Because of a history of social policy that restricted African Americans' admission to the main avenues toward wealth accumulation, black families have less assets than their white peers who earn identical wages (Oliver and Shapiro). Studies have recurrently exposed that lower socioeconomic status and lower academic achievement are related (Nettles, Millett and Ready 215-252). High-poverty, high-minority schools have a bigger probability of having unqualified teachers (Olson 9-16) and have 
a harder time attracting and retaining highly qualified educators (Sunderman and $\mathrm{Kim})$.

In 2009, data from the National Assessment of Educational Progress showed that $36 \%$ of all African American children are poor. Poverty is defined as having family household revenue lower than the federal poverty threshold. The federal poverty threshold for a family of four is \$22,350 (National Assessment of Educational Progress). Poverty has been constantly related to the achievement gap (Martin et al. 689-698). "In truth, all children can learn, but how much they learn depends on socioeconomic conditions as well as school effectiveness" (Rothstein 82). According to the US Department of Commerce, median African American family income is roughly $65 \%$ of the median Caucasian family income, and median African American family net worth is merely around $15 \%$ of Caucasian family net worth. African Americans' overrepresentation in poverty in the United States is noticeable. Some have contended that this is owing to negative stereotypes related to the African American community. Though some of these negative stereotypes might be right for some persons, it should be born in mind that African Americans were enslaved, segregated and disqualified from equal chances for more than a century after the abolition of slavery (Rothstein).

"Being impoverished has important detrimental effects on schooling, including raising the risk of poor performance" (Verdugo 187). A family's socioeconomic status is frequently affected by parent academic attainment (Roscigno "Family/School/Inequality" 266-290). "Living in poverty usually means families are less able to afford good healthcare, secure nutritious food, or provide enriching cultural or educational experiences for their children, all of which are essential preconditions for students to sustain success in school" (Bainbridge and Lasley 426). Underprivileged families are less likely to invest in educational enhancement items, such as educational toys, books, and involvement in educational activities. These investments are related to the cognitive development of children (Kausnal and Nepomnyaschy 963-971).

Socioeconomic status does not merely have an impact on the resources to which students have access in school, but also has an impact on the resources to which students have access at home. Social class has been displayed to affect the aptitude to supply the essential family support for children to succeed academically. There are numerous theories about the interaction of social class and the academic achievement, all of which might shed supplementary light on black-white achievement gaps. It is argued that parents from low socioeconomic backgrounds may grant education a little significance and may be unsuccessful or slightly involved in their children's education. Children may integrate these attitudes, so that they, too, grant only insignificant value on education (Lareau). Another perspective highlights the significance of parents' social networks and affiliations to provide parents with 
the required devices to back their children's education (McNeal 117-144). This social capital perspective accentuates social class as crucial to gaining access to many educational, occupational, and personal openings (Carbonaro 295-313).

According to the third perspective schools are responsible for treating parents of low socioeconomic status differently from those of high socioeconomic status, causing the disengagement of low-income families from their children's education (Epstein and Dauber 289-305). The fourth perspective, based on researcher Bourdieu's cultural capital philosophy, emphasizes that a parent's social class restricts the cultural resources to which he or she has access. Additionally, the resources that low-income parents are capable of offering tend to be ignored or dismissed, in comparison with the resources that better-off families are able to offer (Bourdieu and Passeron).

Stability in household and neighborhood income may have an influence on males in school. Scientists Grogan-Kaylor and Woolley studied 2,099 middle and high school students and revealed that socioeconomic factors lead to school success for students. They also stated that neighborhoods with higher than average household incomes had higher graduation rates; this was particularly true for African American males (875-896). Male students who live in neighborhoods where over $60 \%$ of adults are working in blue collar jobs are three and a half times more likely to fail in high school (Ensminger, Lamkin and Jacobson 2400-2416). Furthermore, investigators Kaushal and Nepomnyaschy revealed in a study of 15,887 students that African American children are roughly twice more likely to repeat a grade than Caucasian children even after socio-demographic features were controlled. They also testified that students from African American families with a net worth of less than $\$ 10,000$ were more likely to repeat a grade. It was also reported that African American families have lower rates of home ownership and monetary savings than Caucasian families. These were also noted to be statistically noteworthy dynamics for school success (963-971).

Advocates of the socioeconomic discrepancies theory find that the black-white achievement gap is essentially produced by class and race factors. They claim that class and race are closely related and that factors linked to class generate inequalities in school and beyond (Davidson). Regarding class, they point out the dissimilarities between the parenting behaviors of lowerclass, middle-class, and professional parents; racial discrimination endured by blacks; housing conditions; and other socioeconomic dynamics as predictors of success. Researchers have exposed that there are discrepancies in education skills between parents of low socioeconomic status and those who hold professional positions. The degree to which parents read to their children, and the quantity and quality of dialogue between parent and child are influential causes of the quality of cognitive development a child will undergo (Paige and Witty 60-61). 
Betty Hart and Todd Risley, two senior researchers with the Schiefelbusch Institute for Life Span Studies at the University of Kansas, investigated the dissimilarity in the quality of parent-child dialogue between professional families, lower-class families, and well-off families. They discovered that language development in young children was tremendously associated with socioeconomic status. Investigating families with infants between one and two years old for two and a half years, they reported their conclusions in their prominent book Meaningful Differences in the Everyday Experience of Young American Children. Children from professional families could have a much higher observed cumulative vocabulary than their peers from welfare and working class backgrounds. Averagely, children from professional families perceived a higher ratio of praise to discouragement than their welfare or working class cohorts. In line with these arguments, Richard Rothstein contends in his book Class and Schools: Using Social, Economic, and Educational Reform to Close the Black-White Achievement Gap that class and socioeconomic factors influence highly a child's cognitive development.

This position itself lays the foundation for the gap. The problem with this way of thinking is that it excuses schools, teachers, and school leaders by implying that the school is not to be held responsible for student achievement because socioeconomic dynamics are the real foundations of underprivileged children's poor academic performance. This line of reasoning is not a part of the solution; it is a root of the problem. Socioeconomic status is far from being an obstruction to success; low socioeconomic status presents challenges, but it does not prevent economic nor educational success. There are countless stories of people who have climbed up from life-threatening poverty and been successful (Paige and Witty 62-63). Moreover, lower test scores for black students are not solely attributable to socioeconomic status and disparities, but also to the culture of underachievement in the black community.

\section{E. Socio-Cultural Attributes}

A wide range of conservative scholars conducted a massive amount of research about the current black-white achievement gap in U.S. public schools and concluded that a considerable number of sociocultural factors- or what is commonly known as Socio-pathological Culture factors- are partly accountable for the issue. They argue that there are existing social ills in the culture of African Americans which impede them from performing highly in schools. They see that home and family variables have a potent effect on children's cognitive development and that negative sociocultural factors do contribute to the difficulties that many African American children experience in school. Some researchers even argued that the family is the primary determining force behind student performance, not schools. For them, parental involvement in children's academic and social lives plays a crucial role in children's academic learning and achievement. They also proclaim that the expectations and 
behaviors shown in the family can have a decisive impact on lower academic performance and that family support and setting early educational goals are two of the strongest predictors for student development and academic success. Others affirm that a student's performance may be enhanced or hindered by a steady or changeable interaction with their parents and that African American children are three times as likely as white children to be raised in low income homes.

At the outset, those who support the notion that sociocultural factors account for the gap believe that there is something inherent in the culture of African Americans that influences academic achievement. The list of social ills that many think are at the origin of the poor academic performance of African Americans comprises: poor parenting skills, unstable families, absence of drive and determination, negative peer pressure, minor parental involvement in children's education, inadequate selection of role models, high levels of teen pregnancies, drugs, and crime (Paige and Witty 63). Social critic Mano Singham employs the phrase "socio-pathological culture" in his article "The Canary in the Mine" to discuss such ills (9-15).

Those who hold traditional philosophical interpretations favor sociocultural explanations for the black-white achievement gap. From their viewpoint, the solution to the achievement gap is found within the control of African Americans themselves. To put it straightforwardly, their philosophy is that African Americans should get rid of whining and complaining and pull themselves up by their personal efforts (Paige and Witty 63). In line with this idea there is research displaying that home and family variables have a solid influence on children's cognitive development (Armor). A child's achievement in school seems to be tightly linked to the extent to which the child's family is able to construct a home environment that boosts learning, transfers high expectations for their children's achievement and future careers, and takes part in the child's education at school and in the community. So obviously, negative sociocultural attributes do contribute to the troubles that numerous African American children undergo in school (Paige and Witty 63-64). However, the present article rejects this as a vital explanation for the black-white achievement gap.

Other investigators center their attention on the family and parenting as significant dynamics in preventing children from dropping through the cracks (Furstenberg et al.). The process of learning starts at home, even before children start to be present at school. Some academics have contended that the family is the main decisive force behind student performance, not schools (Coleman et al.). Parenting includes a diversity of behaviors and roles, including teaching, nurturing, disciplining, setting an example for, and backing children (Brooks-Gunn and Markman 139-168). Recent literature has revealed 
that parental involvement in children's educational and social lives plays a vital role in children's educational learning and attainment (Epstein).

In his research, Ogbu disclosed that despite the fact black parents had high academic expectations for their children; they frequently were limited in their participation in their children's education and extracurricular activities and had low contribution in numerous school organizations and activities planned for parents (Ogbu Black American Students in Suburb). Though theoretically African American parents desired to push their children to be successful academically, they did not manage to be involved in practices that facilitate such success (Furstenberg et al.). Such practices might include the following: teaching time management, monitoring television time, supervision of homework, boosting their children to work hard in school, and teaching children to evade negative pressures. Furthermore, black parents were frequently ignorant of the availability of honors and advanced placement (AP) courses and the importance of enrolling in such courses during high school (Ogbu Black American Students in Suburb).

The family environment has an impact on student achievement. "The family is the first educator of the child, and the school cannot accomplish its purpose without at least the implicit support of the family" (Constable and Lee 220). "The expectations and behaviors exhibited in the family can have an important effect on lower academic performance" (Verdugo 188). Low parental education expectations, parents who dropped out of school, having a peer who dropped out, less parent contact with the school, absence of homework monitoring or study assistances and rare dialogues with a child about school are all related to lower school performance (Verdugo 184-204).

Academics Leach and Williams claim that family support and establishing early educational objectives are two of the most powerful predictors for student development and academic achievement. The academic achievement gap hinders the social and economic progression for the African American family. Leach and Williams go on to assert that bettering the achievement gap would reinforce the African American family. They further argue that without quality education and higher rates of graduation from both high school and post-secondary education, African Americans will be impeded from having social and economic equality (39-59).

In an attempt to determine whether the strength of family relationships affects school results, researcher Shearin conducted a study of 179 African American middle school aged males. His research revealed that a student's Grade Point Average (GPA) together with students' regular homework were major indicators of family relationships. The study further discloses that there is a positive relationship between parent-adolescent interaction and participants' educational achievement. These conclusions reveal that a student's performance may be boosted or hindered by a constant or inconsistent 
interaction with their parents. Shearin declares that when children are raised in a home that fosters a sense of self-worth, competence, welfare and independence, children will be more apt to take the risk to learn (125-137).

Though the minority achievement gap is a race connected gap, it is not determined exclusively by race. The achievement gap is a complicated, interrelating combination of socio-cultural factors. It has been revealed that African American children are three times as likely as white children to be raised in low income homes (Lee 3-12). A minority status in association with poverty reinforces the likelihood of a low educational accomplishment. This is due to these circumstances which have detrimental effects directly linked to schooling. Many of these children receive inappropriate health care and nutrition, they have less educational resources in the home, family members tend to have lower educational accomplishments and hence ignore how to adequately prepare and supervise their child's education, there is a fragile family support system, and these children tend to move more often. All of these factors work against schooling and make educational achievement less of a priority. Wealth and the prospects of higher education accumulate over time. The expectations positioned upon a specific student are influenced by the educational attainment of their parents and grandparents. For those underprivileged children who have difficulty in finding food for dinner, completing an essay or taking a college preparatory class does not appear as significant (Denslow 3).

The significance of socio-cultural dynamics is affirmed in a research conducted by investigator Jaekyung Lee. Lee found that the Black-White gaps in socioeconomic status and family circumstances reduced from 1970-1990 but the reduction decelerated in the late 1980's and 1990's. This acceleration and deceleration of the reduction in family circumstances strictly equals the narrowing and widening of the Black-White achievement gap. Lee discloses that socioeconomic status co-varies and is linked to the achievement gap but it is far to be the sole variable (3-12). Researcher Vincent Roscigno highlights these conclusions in his work on the racial disparities of achievement in 1998. Roscigno found a noteworthy 6.7 point standardized test score variance in math between the achievements of Black students in comparison with the achievement of White students. Thirty percent of this racial gap is explained by family differences. When there is a one percent rise in family income, there is a successive increase in math scores of 0.4 points. Students who possess 50 or more books in the house have a 2.6 point advantage than those students who have no resources at home. Students whose parents have at least a high school certificate have a 2.1 point advantage in math and students living in single parent homes have a 0.7 point disadvantage. Roscigno reveals that socioeconomic attributes do play a crucial role in the discrepancy between minority and non-minority children but these causes are only part of the 
problem. Roscigno found an alarming fourteen percent of the racial gap in math to be explained by educational processes that are not linked to family factors ("Race and the Reproduction of Educational Disadvantage").

Being raised in an environment full of hostile circumstances clearly challenges a child's expectations for success. More detrimental, however, is the tendency of teachers and other educators to center attention on the negative environment of children's background rather than on the strong points that the children have. This opinion emerges out of the huge quantity of research advocating the conclusion that teacher expectations have potent impact on student learning (Rosenthal and Jacobson Pygmalion in the Classroom). The fact that many African American children do succeed academically despite the difficulties presented by societal circumstances, nevertheless, weakens the sociocultural explanation. There are countless instances of individual success stories of African Americans whose resiliency carried them through undesirable institutional and community conditions. Additionally, there are isolated cases of schools in inner-city neighborhoods where high achievement is school wide. The negative sociocultural attributes do not entirely account for the achievement gap; they are in effect hurdles to high achievement, but they can be overwhelmed by good schools (Paige and Witty 64).

Given the intimate relationship between socioeconomic factors and cultural forces as probable attributes that account for the current and persistent disparities between black students and their more affluent white cohorts, the most common question that comes to one's mind is which of culture or social class explains the most the black-white achievement gap? The debate is rather heated among both conservatives and liberals who hold conflicting views regarding the economic and cultural factors. While conservatives proclaim that cultural differences are accountable for the African American students' low performance in schools, liberals do rather assert that economic issues are at the root of the black-white achievement gap problem. In spite of the differing argued divergences about the most probable explanations that lie behind the present academic inconsistencies in U.S. public schools, both of culture and socioeconomic features are so intertwined that they cannot be disjointed.

Whether cultural dynamics or socioeconomic forces, they are not the determinant explanations that laid the foundations for the black-white achievement gap. They both merely constitute one of several other factors, which have already been discussed in the previous sections; namely racism and genetic factors together with black identity and oppositional culture. Taken altogether, they all represent probable explanations of the gap. However, school-based attributes or rather educational factors are to be deemed in this article as the most potential explanations and most determining factors that planted the seeds for the black white academic discrepancies in U.S. public schools. 


\section{F. Educational Factors}

Indeed, the last but most significant explanations that account for the current and persistent achievement gap between blacks and whites in this article are educational factors- or what is commonly known as Educational Deprivation factors. Supporters of this view argue that efficient educational practices are able to overweigh all other external issues and proclaim that offered pedagogical support is key to successful learning. They believe that children motivational problems can be sorted out by highly motivated teachers who are willing to set high standards of educational achievement and to provide good instruction accompanied with emotional acceptance and support. Educational explanations' advocates also assert that great teaching can overcome children's low economic status and that the educational achievement that children accomplish is linked directly to their school and the education they receive; for them it is the school's responsibility to ensure the provision of essential tools and skills for students to navigate the academic environment and that a school's racial climate is a factor in racial disparities in both achievement and discipline.

Exponents of school-based or educational deprivation factors perceive both of tracking and teachers' negative expectations as determinant attributes that lead inevitably to wide academic discrepancies between blacks and whites. For them, the practice of tracking can exacerbate achievement gaps as it inevitably translates into divisions across racial lines. Teachers' perceptions of race together with the lack of availability of sufficient guidance counseling also play a critical role in the achievement gap. In a word, the present article approves the argument that most proponents of the educational factors' theory support; "all children will learn at high levels when they are taught to high levels" (The Education Trust). Educational Deprivation is defined as a child's lack of basics necessary for sound cognitive development, most particularly, high expectations and great teaching. It is noted that those who hold such views find that most efficient educational practices can surmount all other difficulties and that a child's economic conditions, their first language, and the scholastic level of their parents are far from being deterring barriers. It is actually found that all children can learn when supplied with the fitting pedagogical assistance (Paige and Witty 71-72).

The crucial fundamentals of the educational deprivation explanation are brilliantly pronounced by educator, psychologist and chief contributor to the approach that won Brown v. Board of Education in 1954, Kenneth Clark. He places the blame for the huge educational failure of ghetto schoolchildren straightforwardly on teachers and administrations of ghetto schools. To him, every one of the suppositions related to the terms "cultural deprivation and cultural difference" is "primarily an alibi for educational neglect, and in no way a reflection of the nature of the educational process." He proclaims that a basic 
constituent of the deprivation that affects ghetto children is that usually their teachers do not expect them to learn; the teachers perceive their job as being one merely of custodial attention and discipline. He confirms that the motivational issues of these children will be resolved when teachers can be stirred to teach efficiently. Effective teaching consists of setting high standards of educational performance and providing good instruction, along with emotional acceptance and backing (Katz 385).

Clark quite openly objected to the other explanations. He firmly insisted that the achievement gap is a phenomenon that can be surmounted by great teaching. The argument that great teaching can succeed to surmount children's low economic status has massive support. More lately, alumni of Teach for America (TFA) have allegedly adopted comparable views. TFA, an independent nonprofit organization whose task is to enlist America's most talented future leaders in the "movement to eliminate educational inequality," achieves its task by constructing a national corps of exceptional recent college graduates- of all academic majors and career interests- who commit two years of teaching in inner-city and rural public schools in America's lowest-income communities and become permanent leaders for broadening educational opportunity (Teach for America).

A 2005 survey of the TFA corps offers insight into the opinions of its members concerning the reasons for student underachievement. Three conclusions speak straightforwardly to the subject of education deprivation as a justification for the achievement gap: First, Educators have the authority to reduce the achievement gap. Second, expectations of students- from educators, schools, parents, the general public, and students themselves- are a powerful instrument and an influential hurdle alike. Corps members perceive low expectations as an important reason of the achievement gap. They proclaim that increasing a collective belief in the potential of underprivileged students and African American students is essential to close the gap. And third, the general public has an erroneous understanding of issues vis-à-vis the achievement gap. Corps members worry that the public wrongly lays responsibility for the gap on students and their families. They also claim that much of the public is merely ignorant of the presence of this gap or of the realities of poverty and discrimination ("Equity Within Reach").

The educational achievement one completes is linked directly to their school and the education they receive. Once a child is enrolled in school it is the school's duty to guarantee that it is supplying the indispensable tools and skills for students to navigate the educational environment (Horton A. 57-70). "Students, regardless of race, must perceive schooling as legitimate, respectful of them and deserving of their efforts if they are to invest in the forms of achievement expected by schools" (Mattison and Aber 9). A school's discriminatory climate is an attribute in racial discrepancies in both attainment 
and discipline (Mattison and Aber 1-12). Furthermore, schools and teachers have a huge influence on the learning environment children are positioned in. Teachers can recommend students for special education services. Caucasians are far less likely than African Americans to be identified with learning disabilities and retained in obstructive educational settings where they are separated from regular classrooms and nondisabled counterparts (Stearns and Glennie 29-57). Moving students out of regular education classrooms into more limited settings can cause further separation of a minority student which can result in drop out.

Underprivileged students who have a special education label are more probably to be in a constrained, higher federal setting classroom than their Caucasian counterparts. Half of Caucasian students who are in special education spend eighty percent or more of their school day in a general education classroom setting in comparison with only one-third of African American students (Fierros 1-9). The National Education Association (NEA) reveals that the dropout rate for students in special education was twenty nine percent for the subgroup of students labeled EBD, the dropout rate is fifty three percent. Disadvantaged students are more likely to receive referrals to the office, expulsions and suspensions. Of all marginal groups, low income African American males are the most likely to be suspended and African American males are more likely to be severely punished for an identical offence as a Caucasian student (NEA). Besides, African American, Hispanic, and American Indian students who were obtaining special education services were sixty seven percent more likely than their Caucasian partners to be suspended from school by an officer on the basis that they were unsafe (National Education Association). A school with a huge number of minority students is five times more likely to have a low graduation rate in comparison with a majority Caucasian school. Thirty nine percent and 46 percent of Hispanic students and African Americans respectively go to schools where graduation is not the rule (Christie, Jolivette and Nelson 325-339).

Schools play a crucial role in the broadening of the black-white achievement gap. Researcher Diamond offers the subsequent aspects of the racialized terrain of their schools and classrooms: first, African American students are stereotypically educated by less experienced teachers; for instance, uncertified teachers and teachers with restricted experience, than their white peers (Uhlenberg and Brown 493-530). Second, black students are confronted with a wide array of educational handicaps in their schools and classrooms when likened to white students. For instance, they are jammed in inferior educational tracks, which offer students less stimulating course work and produce less learning (Hallinan 79-84). And third, the teachers of black students also hold inferior expectations for them than for other students. 
A large array of schools devise pathways of achievement for some students and not for others via academic leveling and tracking. This practice can intensify achievement gaps because students are often separated according to their perceived ability, which, in practice, frequently transforms into racial divisions. While blacks are frequently, enrolled in lower-level courses, whites are often enrolled in upper-level ones (Ogbu Black American Students in Suburb). Moreover, African American students are inadequately placed in special education courses (Blanchett 24-28), which leads to decreasing their access to significant educational resources. Tracking frequently happens as early as elementary school, which becomes problematic and can account for the widening achievement gap as students continue through their secondary education. Tracking defines a particular pathway for students from which it is frequently tough to break out. Researcher Ogbu concluded that these mechanisms can also have an adverse influence on how students perceive their educational aptitudes: some African American students evaded taking honors and advanced placement courses because they felt the work would be too difficult for them; accordingly, they never gave themselves an opportunity to attempt and succeed (Black American Students in Suburb).

Educators' perceptions of race play a crucial role in the educational expectations teachers hold for their students (Carter). Instructors' sensitivity to race can also have an impact on teaching and molding the experiences of students within their classroom (Kinchloe et al.). Teachers' lower academic expectations of students from a specific race or socioeconomic status can become a self-fulfilling prophecy and produce the reduced academic achievement of those students (Rosenthal et Jacobson "Self-fulfilling Prophecies" 219-253). Race constitutes also a factor in which students are considered as in need of corrective action and in the ways in which teachers attempt to interfere and assist their students (Gregory and Mosely 18-30). The absence of accessibility of adequate guidance counseling may also play an important role in the achievement gap. Counselors usually assist students to choose which courses to take and guide them to center on their academic futures, particularly college. Yet, in underfunded schools, counselors frequently have little time to provide help to students or boost them to take higher-level classes (Ogbu Black American Students in Suburb).

In 1968, an eminent study conducted by authors Rosenthal and Jacobsen, revealed the potent effect teachers have on student achievement. Students were selected to outperform by their teachers, and the students that the educators selected to excel outperformed their counterparts by the end of the school year. The students, who were selected by instructors to succeed, gained an average of fifteen points on their IQ tests. The authors concluded that the consequence could only be owing to teachers' expectations, attitudes and conducts toward the students. This study displayed that the treatment of 
students by teachers augmented test scores irrespective of race or family settings ("Self-fulfilling Prophecies" 219-253). Furthermore, researchers Uhlenberg and Brown conducted a survey, in 2002, of fifty four public school teachers from fourteen dissimilar schools in North Carolina to search teachers' perceptions of the causes of the achievement gap. They reported that Caucasian teachers appeared less supportive of probable resolutions directed to change the behavior of Caucasian teachers, such as enlisting African American teachers or receiving different training. It was also revealed that Caucasian teachers find that recurrent misconduct of African American students led to their lack of learning. On average, the teachers surveyed consented that teacher quality has little to do with certification. Both African American and Caucasian teachers approved that certification of teachers does not influence the quality of teaching they offer (493-530).

High poverty and majority- minority schools have less-experienced, less-educated, and less-qualified teachers (Fram, Miller-Cribbs and Van Horn 309-319). Schools with typically minority students and a high rate of poverty are more likely to have jammed classrooms and less access to technology (Rothstein). In an attempt to magnetize teachers with more experience, more education, advanced subject specific preparation and advanced cultural proficiency, all combined with positive impact on students learning, schools may be required to offer motivations. For the time being, there are no incentives for highly- experienced and high performing teachers to change professions (Fram, Miller-Cribbs and Van Horn 309-319). Additionally, in an article written by authors Grossman, Beaupre, and Rossi and titled "Poorest kids often wind up with the weakest teachers," it was claimed that children who descend from underprivileged families frequently have the least qualified teachers. Virtually fifty percent of all Illinois public school teachers were part of the research that revealed that children in the highest performing, lowest poverty and lowest minority schools were five times less likely to be educated by instructors who failed at least one teaching certification test than children in the lowest performing, highest poverty and highest minority schools.

A Washington D.C.-based independent nonprofit organization, named the Education Trust, is an extra foundation for the great teaching argument. It is actually an additional potent basis of backing for the insight that educational deprivations are a key cause of the achievement gap. One of the Education Trust's beliefs is: "All children will learn at high levels when they are taught to high levels" (The Education Trust). Its mission proclamation compels this independent nonprofit education organization to working "for the high academic achievement of all students at all levels, pre-kindergarten through college, and forever closing the achievement gaps that separate low-income students and students of color from other youth" (The Education Trust). Among the Education Trust's numerous contributions to scholastic equality is 
its effort in ameliorating teacher quality. Its leaders highlight that teachers matter most in the endeavor to narrow the achievement gap. During testimony before the Commission on No Child Left Behind, Russlynn Ali, Director of Education Trust West, called the attention of the commission by asserting that "the most effective teachers can teach even the most disadvantaged students up to high standards, but a couple of ineffective teachers in a row can hobble a student's education for years to come" (Russlynn).

In reality, there exists a large array of contradictory opinions to account for the black-white achievement gap. Each view is rather contingent on countless diverse variables but the whole issue is about whether or not one believes all children can learn. This is, in effect, the determinant of which justification of the gap's existence one finds most compelling. The main source of the African American-white achievement gap is that low-achieving students have been denied the educational fundamentals which support learning to high levels. Every child has the capacity to study at high levels when they are educated at high levels. The children placed on the undesirable side of the gap endure educational deprivation. They have not been instructed at high levels. Being educated to high levels equals educational backing from dynamics outside of the school. It encompasses the support and commitment from the whole teaching trio- home, school, and community (Paige and Witty 73-74). After reflecting on the cause of the gap's existence, researchers Paige and Witty raised a new question about the cause of the gap's persistence. On the issue, they provided several grounds:

It persists because it has been allowed to. It persists because it's a problem that nobody owns. It persists because we, who should be the rightful owners of the problem, have yet to identify it as a problem worthy of our full attention. It persists because, failing to recognize its importance to the advancement of African Americans toward the twin goals of racial equality and social justice in America, we - the African American leadership community - have our heads in the sand. (74)

Clearly, the black-white achievement gap in U.S. public education is the outcome of diverse arguments and numerous theories, ranging principally from educational factors, socioeconomic attributes, sociocultural dynamics, and even from allegedly-objective or rather racist attitudes. In spite of the massive amount of deeply-conducted research and the considerable number of potently offered arguments in support of these theories, they remain mere potential explanations, and there is no single universal explanation that accounts for the gap between blacks and whites in schools. In the present article, however, educational factors are much more relevant to the issue under examination and are deemed as the most probable, but never single, explanation of the black white discrepancies in U.S. public education. Furthermore, digging deeper into 
the American distant history of slavery, Jim-Crowism and discrimination helps put the black-white achievement gap issue into its historical setting and thus provides further probable explanations or rather origins.

\section{Conclusion}

Many obstructive underlying forces present in the African American educational experiences contribute to the limitation of their opportunities of academic achievement. Indeed, scientists and theoreticians have scrutinized most features of human character, behavior, and endeavor to try to identify significant correlates and cures for the massive variance between African American and white student achievement. Included among the most distinguished recurrent explanations are racism, genetic factors, black identity, oppositional culture, socio-economic status and discrepancies, socio-cultural attributes, and educational factors. Some investigators contend that academic achievement restraints confronted by African Americans as a result of the racial stratification of society are at the origin of the gap. Others argue that genetics simply did not bestow blacks with enough cerebral horsepower to compete scholastically with whites. Furthermore, the eminent American anthropologist John Ogbu believes that there are three forces within the African American community that account for low achievement among black students: black folk theories of effort and reward, black relational adaptations, black belief that school learning is "acting white." Moreover, advocates of the socioeconomic disparities assert that educational performance correlates more intensely with economic status than with any other single variable. They claim that class and race are intimately linked and that attributes associated with class devise disparities in school and beyond.

Furthermore, those who approve that sociocultural attributes explain the gap claim that there is a list of social ills that are inherent in the culture of African Americans and that militate against academic attainment. However, the debate about whether the low achievement of black students is entrenched in culture or economics is largely unrewarding because socio economic status and culture cannot be disjointed. We argue in this article that school-based factors or educational deprivation are deemed as the most potential explanations for the black-white achievement gap in U.S. public education. Those who hold such beliefs believe that operational educational practices can surmount all other problems. They find that all children can learn when provided with the proper pedagogical sustenance. They affirm that the educational achievement one completes is linked directly to their school and the education they obtain. Thus, the practice of academic leveling and tracking of students can exacerbate achievement gaps because students are often divided on perceived aptitude which frequently translates into divisions across racial lines. Teachers' perceptions of race also play a crucial role in the educational expectations teachers hold for their students. 


\section{Works Cited}

"Equity Within Reach: Insights from the Front Line of America's Achievement." Teach for America Report. 2005. Web. 14 Aug. 2013.

American Anthropological Association. Statement on Race and Intelligence. Dec. 1994. Web. 13 Aug. 2014.

American Psychological Association. The View of the American Psychological Association. 2008.Web. 14 Aug. 2015.

Armor, David J. Maximizing Intelligence. New Brunswick, N.J.: Transaction Publishers, 2003. Print.

Bainbridge, W. L., Lasley, T. J. "Demographics, Diversity, and K-12 Accountability: The Challenge of Closing The Achievement Gap." Education and Urban Society 34.4 (2002): 422-437. Print.

Bankston, C.L.I. and Caldas, S.J. "Majority African American Schools and Social Injustice: The Influence of Desegregation on Academic Achievement." Social Forces 75.2 (1996): 535-555. Print.

Binet, Alfred. The Development of Intelligence in Children: The Binet-Simon Scale. Baltimore: Williams and Wilkins Co., 1916. Print.

Blanchett, W.J. "Disproportionate Representation of African American Students." Special Education: Acknowledging The Role of White Privilege and Racism. Educational Researcher 35. 6 (2006): 24-28. Print.

Bonilla-Silva, E. White Supremacy and Racism in the Post-Civil Rights Era. Boulder, CO: Lynne Rienner. 2001. Print.

Bourdieu, P., and J.C.C. Passeron. Reproduction in Education, Society, and Culture. $2^{\text {nd }}$ ed. Beverly Hills, CA: Sage. 1990. Print.

Brooks-Gunn, J., and Markman, L.B. "The Contribution of Parenting To Ethnic and Racial Gaps In School Readiness." The Future of Children 15. 1 (2005): 139168. Print.

Carbonaro, W.J. "A Little Help From My Friends' Parents: Intergenerational Closure and Educational Outcomes." Sociology of Education 71. 4 (1998): 295-313. Print.

Carter, P.L. Keeping It Real: School Success Beyond Black and White. New York: Oxford University Press: 2005. Print.

Christie, C. A., Jolivette, K. and Nelson, C. M. "School Characteristics Related To High School Dropout Rates." Remedial and Special Education 28 (2007): 325-339. Print.

Chubb, J.E., and T. Loveless. Eds. Bridging the Achievement Gap. Washington, DC: Brookings Institution Press, 2002. Print

Coleman, Geraldine. Issues in Education. Westport, Connecticut: Bergin and Garvey, 2001. Print.

Coleman, J.S., E.Q. Campbell, C.J. Hobson, J. McPartland, A.M. Mood, F.D. Weinfeld, et al. Equality of Educational Opportunity. Washington, DC: U.S. Government Printing Office. 1966. Print.

Constable, R., and D.B. Lee. Social work with families: Content and process. Chicago: Lyceum Books, Inc. 2004. Print.

Davidson, Jill. "A Review of Rothstein's Class and Schools: Using Social, Economic, and Educational Reform to Close the black-white Achievement Gap." Horace Book Review. 21, no. 2 (Winter 2005). 362. Web. 26 Aug. 2015. 
Denslow, Katie. The Ability of Teachers to Close the Minority Achievement Gap through Multicultural Teacher Training. Carleton College: May 2000. Print.

Diamond, J.B. Are We Barking Up The Wrong Tree? Rethinking Oppositional Culture Explanations For The Black/White Achievement Gap. Paper Presented at the Achievement Gap Initiative. Harvard University. 2006. Print.

Diamond, J.B., and Spillane, J.P. "High-stakes Accountability In Urban Elementary Schools: Challenging or Reproducing Inequality?" Teachers College Record 106. 6 (2004): 1145-1176. Print.

Ensminger, M. E., Lamkin, R. P., and Jacobson, N. "School Leaving: A Longitudinal Perspective Including Neighborhood Effects." Child Development 67(1996): 2400-2416. Print.

Epstein, J. L. School, Family, and Community Partnerships: Preparing Educators and Improving Schools. Boulder, CO: Westview Press. 2001. Print.

Epstein, J.L., and Dauber, S.L. "School Programs and Teacher Practices of Parent Involvement In Inner-City Elementary And Middle Schools." Elementary School Journal 91. 3 (1991): 289-305. Print.

Fierros, E. G. "One Size Does Not Fit All: A Response To Institutionalizing Inequality." Disabilities studies Quarterly 26.2 (2006):1-9. Print.

Fordham, Signithia and John Ogbu, "Black Students' School Success: Coping with Burden of Acting White." Urban Review 18. 3 (1986): 176-206. Print.

Fram, M. S., Miller-Cribbs, J. E., and Van Horn, L. Poverty, Race and The Contexts of Achievement: Examining Educational Experiences of Children in the U.S. South. National Association of Social Workers. 52.4 2007: 309-319. Print.

Furstenberg Jr., F.F., T.D. Cook, J. Eccles, Elder Jr., G.H., and A. Sameroff. Managing to Make It: Urban families and adolescent success. Chicago: The University of Chicago Press. 1999. Print.

Gregory, A., and Mosely, P.M. "The Discipline Gap: Teachers' Views on The Overrepresentation of African American Students In The Discipline System.” Equity and Excellence in Education 37.1 (2004): 18-30. Print.

Grogan-Kaylor, A., and Wooley, M. E. "The Social Ecology of Race and Ethnicity School Achievement Gaps: Economic, Neighborhood, School, and Family Factors." Journal of Human Behavior in the Social Environment 20.7 (2010): 875-896. Print.

Grossman, K., Beaupre, B., and Rossi, R. "Poorest Kids Often Wind up with the Weakest Teachers." Chicago Sun-Times. 7 Sept. 2001. Web. 15 Oct. 2014.

Hallinan, M. T. "Tracking: From Theory To Practice." Sociology of Education 67.2 (1994): 79-84. Print.

Hart, Betty and Todd R. Risley. Meaningful Differences in the Everyday Experience of Young American Children. Baltimore, Md.: Paul H. Brookes Publishing Company, 1995. Print.

Haycock, K. National Assessment of Educational Progress (NAEP). 2001. Web. 4 Oct. 2012.

Herrnstein, Richard J. and Charles Murray. The Bell Curve. Intelligence and Class Structure in American Life. New York, N.Y.: Free Press, 1994. Print.

Horton, A. "The Academic Achievement Gap Between Blacks And Whites: The Latest Version Of Blaming The Victim?" Journal Of Human Behavior In The Social Environment 10.2 (2004): 57-70. Print. 
Katz, Irwin . "Alternatives to a Personality-Deficit Interpretation of Negro UnderAchievement." Psychology and Race. Ed. Peter Watson. Chicago: Aldine Publishing Company, 1997. 385. Print.

Kaushal, N. and Nepomnyaschy, L. Wealth, Race/Ethnicity, and Children's Educational Outcomes. Children And Youth Services Review 31 (2009): 963971. Print.

Kinchloe, J.L. Steinberg, S.R., Chennault, R.E., and Rodriguez, N.M. Eds. White Reign: Deploying Whiteness in America. New York: St. Martin's Press. 1998. Print.

Laureau, A. Home advantage. New York: Falmer Press. 1989. Print.

Leach M. T., and Williams, S. A. (2007). "The Impact of The Academic Achievement Gap on The African American Family: A Social Inequality Perspective." Journal of Human Behavior in the Social Environment 15 (2007): 39-59. Print.

Lee, J. "Racial and Ethnic Achievement Gap Trends: Reversing the Progress Toward Equality?" Educational Researcher 31.1 (January 2002): 3-12. Print.

Martin, D., Martin, M., Gibson, S. S. and Wilkes, J. "Increasing Prosocial Behavior and Academic Achievement Among Adolescent African American Males." Adolescence 42.168 (2007): 689-698. Print.

Mattison, E. and Aber, M.S. "Closing The Achievement Gap: The Association of Racial Climate With Achievement and Behavioral Outcomes." American Journal of Community Psychologists 40 (2007): 1-12. Print.

McNeal, R.B., Jr. "Parental Involvement as Social Capital: Differential Effectiveness on Science Achievement, Truancy, and Dropping Out." Social Forces 78.1 (1999):117-144. Print.

McWhorter, John. Losing the Race: Self Sabotage in Black America. New York: Harper Perennial, 2001. Print.

National Assessment of Educational Progress. U.S. Department of Education. National Center for Education Statistics. The Condition of Education 2010. Web. 12 Nov. 2015.

National Education Association. Truth in Labeling: Disproportionality in Special Education. Washington, DC: Library of Congress. 2007. Print.

Nettles, M. T., Millett, C. M., and Ready, D. D. "Attacking the African Americanwhite Achievement Gap on College Admissions Tests." Ed. D. Ravitch. Brookings Papers on Education Policy. Washington, DC: Brookings Institution. 2003. 215-252. Print.

Obama, Barack. "The Audacity of Hope." 2004 Democratic National Convention: Boston, Mass., 27 July 2004. Web. 14 Aug. 2012.

Ogbu, John U. Black American Students In An Affluent Suburb: A Study of Academic Disengagement. Mahwah, NJ: Lawrence Erlbaum. 2003. Print.

---. "Racial Stratification and Education in the United States: Why Inequality Persists," Teachers College Record 96.2 (1994): 264-298. Print.

Oliver, M.L., and Shapiro, T.M. Black Wealth/White Wealth: A New Perspective on Racial Inequality. New York: Routledge. 1995. Print.

Olson, L. "The Great Divide.” Education Week 22.17, 2003: 9-16. Print. 
Orfield, G., and Eaton, S.E. "The Growth of Segregation." Eds. G. Orfield and S. Eaton. Dimantling Desegregation. The Quiet Reversal of Brown v. Board of Education. New York: The New Press. 1996. 424. Print.

Osborne, Jason W. "Testing Stereotype Threat: Does Anxiety Explain Race and Sex Differences in Achievement?" Contemporary Educational Psychology 20 (April 2001): 291-310. Print.

Paige, Rod, and Elaine Witty. The Black-White Achievement Gap: Why Closing it is the Greatest Civil Rights Issue of Our Time. New York: American Management Association. 2010. Print.

Roscigno, Vincent J. "Family/School Inequality and African-American/Hispanic Achievement." Social Problems 47.2 (2000): 266-290. Print.

---. "Race and the Reproduction of Educational Disadvantage." Social Forces (March 1998): n.pag. Print.

Rosenthal, Robert and Lenore Jacobson. "Self-fulfilling Prophecies in the Classroom: Teachers' Expectations as Unintended Determinants of Pupils Intellectual Competence.” Eds. M. Deutsch, I. Katz, and A. R. Jensen. Social Class, Race, and Psychological Development. New York: Holt, Rinehart, and Winston. 1968. 219253. Print.

-- Pygmalion In The Classroom: Teacher Expectation and Pupils' Intellectual Development. New York: Holt, Rinehart and Winston, 1968. Print.

Rothstein, Richard. Class and Schools: Using Social, Economic, and Educational Reform to Close the Black-White Achievement Gap. San Diego, California: Economic Policy Books, 2004. Print.

Russlynn, Ali. Presentation, Commission on No Child Left Behind. US Department of Education. Washington, D.C., 11 April 2006. Web. 19 Aug. 2015.

Schiller, Ben. "Learning Their Letters: Critical Literacy, Epistolary Culture, and Slavery in the Antebellum South." Southern Quarterly 45.3 (Spring 2008): 11 29. America: History and Life, Ebscohost. Web. 28 Oct. 2014.

Shearin, S. A. "Parent-Adolescent Interaction: Influence on the Academic Achievement of African American Adolescent Males." Journal of Health and Social Policy 16 (2002): 125-137. Print.

Singham, Mano. "The Canary in the Mine.” Phi Delta Kappan 80. 1 Sept. 1998: 9-15. Print.

Stearns, E., and Glennie, E. J. "When and Why Dropouts Leave High School." Journal of Youth and Society 38 (2006): 29-57. Print.

Sunderman, G.L., and Kim, J. Teacher Quality: Equalizing Educational Opportunities and Outcomes. The Harvard University Civil Rights Project. Cambridge, MA: 2005. Print.

Teach for America. About Us. 2008. Web. 14 Aug. 2014.

The Education Trust. What is the Education Trust? 2008. Web. 14 Aug. 2013.

Thernstrom, Stephan and Abigail Thernstrom. No Excuses: Closing the Racial Gap in Learning. New York: Simon and Schuster, 2003. Print.

Tyson, K., Darity, W., and Castellino, D.R. "It's Not “A Black Thing”: Understanding The Burden of Acting White and Other Dilemmas of High Achievement." American Sociological Review 70.4 (2005): 582-605. Print. 
U.S. Department of Commerce, Census Bureau. Families Below Poverty Level by Selected Characteristics: 2009 Detailed Tables. Table 715. Washington, D.C., 2008. Web. 27 Nov. 2015.

Uhlenberg, J., and Brown, K.M. "Racial Gap In Teachers' Perceptions of The Achievement Gap." Education and Urban Society 34.4 (2002): 493-530. Print.

Verdugo, R. R. "The Heavens May Fall: School Dropouts, The Achievement Gap, and Statistical Bias.” Education and Urban Society 43.2 (2011): 184-204. Print. 